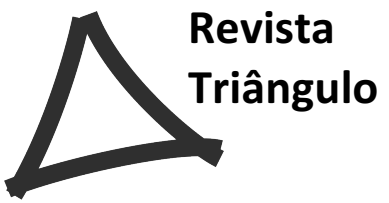

\section{O ENSINO DE ARTE E A MÍDIA-EDUCAÇÃO: UMA PESQUISA EM TESES E DISSERTAÇÕES NOS ÚLTIMOS 10 ANOS}

\section{THE ART EDUCATION AND THE MEDIA-EDUCATION: A RESEARCH ON THESES AND DISSERTATIONS IN THE LAST 10 YEARS}

\author{
Lizandra Calife Soares ${ }^{1}$ e Alexandra Bujokas de Siqueira ${ }^{2}$
}

\begin{abstract}
RESUMO
$\mathrm{O}$ artigo tem como objetivo explorar aspectos comuns entre os campos da mídia-educação e da arte-educação materializados em teses e dissertações brasileiras defendidas nos últimos 10 anos e disponibilizadas no banco de dados do portal eletrônico da Comissão de Aperfeiçoamento de Pessoal de Nível Superior, órgão do Ministério da Educação (CAPES/MEC). Os dados recolhidos e discutidos ajudam a construir a fundamentação teórica de uma pesquisa maior que se compromete em desenvolver abordagem multidisciplinar para o ensino de arte no currículo do Ensino Médio. Elaborado a partir da pesquisa de caráter bibliográfico do tipo "estado da arte", ou "estado do conhecimento", o artigo aponta modos de interconexão entre arte/educação e mídia-educação, via aporte conceitual focado nas artes visuais e na crítica de arte.
\end{abstract}

Palavras-chave: Crítica de arte. Arte-educação. Artes visuais. Mídia-educação.

\begin{abstract}
The article explores commonalities between the fields of media education and art education materialized in Brazilian theses and dissertations published in the last ten years and available in the electronic database system of the so-called CAPES, an agency of the Ministry of Education in charge of the postgraduate regulation in Brazil. The collected data help to build the theoretical basis for further research; that is committed to developing a multidisciplinary approach to art education in Secondary Schools core curriculum. Drawn from the bibliographic research of the "state of the art " or "state of knowledge" procedures, the article points out ways of interconnection between art education and media education, via conceptual contribution focused on the visual arts and art criticism.
\end{abstract}

Keywords: Art criticism. Art education. Visual arts. Media education.

\footnotetext{
${ }^{1}$ Universidade Federal do Triângulo Mineiro - UFTM. E-mail: licalifes@hotmail.com

${ }^{2}$ Universidade Federal do Triângulo Mineiro - UFTM. E-mail: alexandra.bujokas@midiaeducacao.net
} 


\section{INTRODUÇÃO}

Este artigo apresenta resultados preliminares de pesquisa mais ampla intitulada Ensinar crítica de arte no ensino médio usando metodologias de mídia-educação, desenvolvida como projeto de dissertação para o mestrado do Programa de Pós-Graduação da Universidade Federal do Triângulo Mineiro, do Estado de Minas Gerais (UFTM/MG). Aqui, são sumarizados e discutidos dados levantados para fins de elaboração da fundamentação teórica, usando-se aportes metodológicos de pesquisa do tipo "estado da arte" ou "produção de conhecimento", que segundo Ferreira (2002, p. 259), possibilita a organização de fontes sobre um determinado tema, e em um tempo de realização específico.

Com a proposta de investigar, em teses e dissertações disponíveis no banco de dados do portal da CAPES nos últimos 10 anos, a relação e as interconexões entre os termos arteeducação e suas derivações, tais como artes visuais e crítica de arte, com o campo da mídiaeducação, esta pesquisa traz à tona dados que possibilitam um julgamento em termos de características marcantes e tendências do conhecimento produzido na interconexão delimitada.

Devido à amplitude conceitual dos termos centrais, arte/educação e mídiaeducação, a pesquisa foi objetivada, considerando os conceitos de crítica de arte e artes visuais, como delimitadores do termo arte/educação. Esse recorte se justifica porque a arte se concretiza por meio de uma diversidade de linguagens que contemplam a teatral, musical, plástica, a dança, a literária, a cinematográfica, arquitetônica, a digital e até hibridismos que mesclam duas ou mais dessas linguagens, como acontece na performance, só para ficar em um exemplo. Assim, foi preciso encontrar um denominador comum, dadas as características do objeto da pesquisa, que irá focar a arte contemporânea, em suas manifestações visuais.

O termo arte é, de acordo com Jorge Coli (1995), difícil de conceituar, sendo um conjunto de manifestações representadas pelos seres humanos que culturalmente correspondem à uma ideia, proporcionando condições estéticas de apreensão, percepção e fruição. E, "constrói, com elementos extraídos do mundo sensível, um outro mundo, fecundo em ambiguidades [...]capaz de atingir e enriquecer nossa sensibilidade.” (COLI, 1995, p. 110)

Com a expansão histórica e cultural artística, e as experimentações que foram assimiladas no pós-modernismo, a arte foi classificada como contemporânea, sendo os avanços tecnológicos dos suportes e as técnicas aplicadas pelos artistas, denominadas de visuais. O que no circuito de arte significa criar possibilidades entre formas de fazer 
tradicionais com as contemporâneas. Arte visuais é, portanto, uma denominação que posiciona os meios de comunicação e as mídias digitais como possibilidades de renovação no contexto artístico, ampliando as formas de percepção, e fruição das artes.

Toda arte representa a relação entre espectador e obra, essa forma de comunicação, é mediada por teorias e por críticas de arte. Com o intuito de construir, transformar e modelar as visões e as interpretações acerca do que se foi produzido. Coli (1995, p. 13) afirma que, "a crítica, portanto, tem o poder não só de atribuir o estatuto de arte a um objeto, mas de o classificar numa ordem de excelências, segundo critérios próprios. Existe mesmo uma noção em nossa cultura, que designa a posição máxima de uma obra de arte nessa ordem: o conceito de obra-prima."

Desse modo, a arte e as obras de arte para serem apreendidas, percebidas, e fruídas necessitam de mediação, tanto de um olhar crítico, que produzirá outros olhares críticos. Quanto o auxílio do olhar de quem ensina. O educador, neste caso, acrescenta valores e transmite os saberes, trabalhando com a percepção do público, relacionando arte com educação formal ou informal. Ana Mae Barbosa em entrevista para o programa "Roda viva" da T.V Cultura e financiado pela Fundação de Ampara à Pesquisa do Estado de São Paulo (FAFESP), definiu o que é o papel do arte/educador e qual o sentido do termo arte/educação:

Para mim, Arte/Educação é todo e qualquer trabalho consciente para desenvolver a relação de públicos (crianças, comunidades, terceira idade, etc.) com a arte. Ensino de arte tem compromisso com continuidade e currículo, quer seja educação formal ou informal. Arte educação foi o termo usado por meus mestres. Eu acrescentei o hífen, Arte-Educação, no momento em que a arte era recusada pelos educadores, nos anos de sua introdução obrigatória no currículo escolar, em torno de 1973-1974, para dar ideia de diálogo e mútuo pertencimento entre as duas áreas. Na época, meus mestres gostaram da ideia. Recentemente, em 2000, um linguista nos aconselhou a usar a barra, pois este sinal, sim, é que significa mútuo pertencimento. Tanto é assim que a barra é muito usada em endereço de sites, quando um assunto específico está dentro de um outro mais amplo. Mas Arte/Educação e ensino de arte são faces diferentes de uma mesma moeda, a moeda concreta da intimidade da arte. (BARBOSA, 1998)

Ao considerado que a arte e a crítica de arte se relacionam com a educação, com a transmissão e mediação, pode-se afirmar que os mecanismos de comunicação e as mídias, portanto, perpassam os contextos da arte. Possibilitando a conjunção da cultura com o mundo visual. É possível discutir arte através das influências, e associações com as mídias. Sendo 
importante, proporcionar a reflexão crítica desses dois saberes, demonstrando a amplitude conceitual do fazer, do criar e do apreciar, confluindo para os caminhos transitórios entre as linguagens.

O campo da mídia-educação, embora ainda não ainda possua delimitações e epistemologia tão amadurecidos como o campo da arte-educação, constitui-se em um terreno fértil para a pesquisa acadêmica em Educação, já que desde suas origens, esteve vinculada às demandas por pluralidade, diversidade, equilíbrio e democratização do acesso à informação e ao conhecimento, obtidos principalmente com a ampliação da participação do público na esfera da produção de conteúdo e não apenas na fruição das mensagens. É aqui que mídiaeducação e arte-educação se encontram, materializadas em uma proposta de ensinar crítica de arte no Ensino Médio, usando plataformas digitais.

Historicamente, a configuração da prática que hoje se mídia-educação tem uma referência de origem na criação da chamada "Comissão Internacional para o Estudo dos Problemas da Comunicação", que publicou, em 1980, o relatório "Um mundo, muitas vozes" (UNESCO, 1983). Em artigo escrito para subsidiar as discussões da comissão, Jacques Dessaucy, já em 1978, enfatizava a falta de equilíbrio de poder entre o público e os produtores de conteúdo. No contexto das "velhas mídias", cabia aos produtores expressar e ao público receber o conteúdo da expressão profissional. A saída para equilibrar tal desigualdade, segundo Dessaucy consistia em transformar os receptores da mídia em "parceiros", e uma via prática para essa transformação estava nas ações de educação para a comunicação, que se concretizaria em duas frentes: 1. Habilitar os "parceiros" para interagir com mensagens recebidas, através da crítica, e 2. Habilitá-los a produzir conteúdo para os canais existentes, ou criar seus próprios canais participativos e comunitários.

Oito anos mais tarde, James D. Halloran e Marcia Jones (1986) produziram também para a Unesco o relatório "Aprendendo sobre a mídia - mídia-educação e pesquisa em comunicação". Um ponto destacado pelos autores era o de que a mídia-educação fosse baseada na compreensão dos processos de comunicação, compreensão essa que só poderia ser depreendida da pesquisa científica, numa abordagem holística. E, como os paradigmas científicos da pesquisa eram variados, as abordagens da mídia-educação também pareciam variar bastante. A diferença mais marcante, segundo Halloran e Jones, consistia nas abordagens que eles chamaram de "inoculação" e de "preparação" para se relacionar com a mídia. 
Em uma análise nas publicações mais recentes é indicado que essas duas vertentes coexistem até mesmo na época das "novas mídias" e da web 2.0. Neste cenário, a mídiaeducação amplia seu alcance e renova sua relevância, principalmente em função da facilidade de receber, produzir e transmitir conteúdo.

Segundo Jenkins (2008) para participar dessa nova paisagem midiática, é preciso aprender a navegar por modos de representação diferentes e até conflitantes, aprender a fazer escolhas conscientes sobre as formas mais adequadas de expressar ideias em cada contexto e, com isso, ser capaz de fazer uso controlado pela própria vontade da diversidade de ferramentas e linguagens que estão à disposição.

Dessa forma, as duas áreas do conhecimento aqui aproximadas podem trazer à tona possibilidades de conexões e relações que perpassam os saberes, relacionando a produção, apreciação e contexto com experimentação, decodificação e informação. O objetivo é o de evidenciar esta afirmação, cuja pesquisa diagnosticará o modo e as características das produções acadêmicas, inventariando e analisando a relação entre arte/educação, crítica de arte e mídia-educação.

\section{PROCEDIMENTOS METODOLÓGICOS}

Após objetivar e problematizar a pesquisa, a metodologia utilizada apresenta caráter bibliográfico, com abordagem qualitativa, sendo, do tipo "estado da arte". No qual a proposta é realizar uma revisão bibliográfica em dissertações e teses, produções do conhecimento acadêmico, dispostos no portal eletrônico da Comissão de Aperfeiçoamento de Pessoal de Nível Superior, órgão do Ministério da Educação (CAPES/MEC), e que foram defendidas nos programas de Pós-Graduação em Educação, em Arte e outros, no Brasil, entre os anos de 2005 a 2015.

Foram utilizados os recursos "buscar assunto", mais especificamente em "busca avançada", selecionando na janela de especificidade da busca, os itens “qualquer", "contém” e "and", para associar os termos chave e, iniciar a pesquisa. Cujo termos são: Arte/educação “and” mídia-educação, crítica de arte "and" mídia-educação, artes visuais "and” mídiaeducação. Ainda foram destacados os recursos no portal CAPES para refinar os resultados, como o da tipologia, sendo "dissertations" - que mapeia apenas as dissertações e as teses dispostas no portal — e, a data de publicação, permeando os anos de 2005 a 2015. 
Ao realizar a busca com as palavras Arte/educação "and” mídia-educação foi encontrada 01 dissertação, que analisa a Arte literária. Sendo, portanto, mapeado neste termo chave, zero pesquisas que, reúne o foco desse trabalho. Como critério para a seleção de pesquisas, foi pautado o objetivo de encontrar produções que discutem as artes visuais, mais precisamente, no discurso crítico do ensino de arte, relacionando-os à mídia-educação.

Dessa maneira, foram buscados os outros termos chave, como mostra a tabela 1. No qual, crítica de arte "and" mídia-educação mapeou 11 pesquisas, dentre elas, após a leitura dos resumos, foram escolhidas 03 produções. Com o termo artes visuais "and" mídiaeducação, foram encontradas 23 pesquisas e, escolhidas 06 para análise.

Tabela 1 - Dissertações e teses selecionadas de acordo com os termos de busca

\begin{tabular}{|c|c|c|c|c|c|c|c|c|}
\hline$\dot{z}$ & $\begin{array}{l}\text { ANO/ } \\
\text { TIPO }\end{array}$ & $\begin{array}{l}\text { TERMO DE } \\
\text { BUSCA }\end{array}$ & TÍTULO & AUTOR & $\begin{array}{c}\text { ORIENTADO } \\
\mathbf{R}\end{array}$ & INST. & P.P.G & $\begin{array}{l}\text { PALAVRAS- } \\
\text { CHAVE }\end{array}$ \\
\hline- & $\begin{array}{c}\text { 2012/ } \\
\text { Mestrado }\end{array}$ & $\mathrm{CA} / \mathrm{ME}$ & $\begin{array}{c}\text { AaaS: uma } \\
\text { nova condição } \\
\text { para criar, } \\
\text { conhecer, } \\
\text { comunicar }\end{array}$ & Vanessa Lopes & $\begin{array}{l}\text { Prof. }{ }^{\mathrm{a}} \text { Dr. } \\
\text { Christine } \\
\text { Greiner }\end{array}$ & $\begin{array}{l}\mathrm{PUC} / \\
\mathrm{SP}\end{array}$ & $\begin{array}{l}\text { P.P.G em } \\
\text { comunicação } \\
\text { e semiótica }\end{array}$ & $\begin{array}{c}\text { Condição pós-mídia; } \\
\text { Cultura-mundo; } \\
\text { Trabalho imaterial; } \\
\text { SOA; } \\
\text { AaaS }\end{array}$ \\
\hline$N$ & $\begin{array}{c}2010 / \\
\text { Doutorado }\end{array}$ & $\mathrm{CA} / \mathrm{ME}$ & \begin{tabular}{|c|} 
Relato de outra \\
modernidade: \\
contribuições \\
para uma \\
reflexão crítica \\
sobre a \\
mediação da \\
arte no \\
contexto da \\
globalização \\
cultural \\
\end{tabular} & $\begin{array}{c}\text { Vinicius Pontes } \\
\text { Spricigo }\end{array}$ & $\begin{array}{c}\text { Prof. Dr. Martin } \\
\text { Grossmann }\end{array}$ & $\begin{array}{l}\text { USP/ } \\
\text { SP }\end{array}$ & $\begin{array}{l}\text { P.P.G em } \\
\text { Cultura e } \\
\text { Informação }\end{array}$ & $\begin{array}{l}\text { Bienal de São Paulo; } \\
\text { Curadoria de Arte } \\
\text { Contemporânea; } \\
\text { Documenta de } \\
\text { Kassel; } \\
\text { Globalização } \\
\text { Cultural. }\end{array}$ \\
\hline m & $\begin{array}{c}2008 / \\
\text { Doutorado }\end{array}$ & $\mathrm{CA} / \mathrm{ME}$ & \begin{tabular}{|c|} 
O foco da \\
crítica: arte e \\
verdade na \\
Correspondênci \\
a entre Adorno \\
e Benjamin \\
\end{tabular} & $\begin{array}{l}\text { Lucianno } \\
\text { Ferreira Gatti }\end{array}$ & $\begin{array}{l}\text { Prof. }^{\text {a }} \text { Dr. } \\
\text { Jeanne Marie } \\
\text { Gagnebin de } \\
\text { Bons }\end{array}$ & UNICAMP/SP & $\begin{array}{l}\text { P.P.G em } \\
\text { Filosofia e } \\
\text { Ciências }\end{array}$ & $\begin{array}{l}\text { Adorno; Benjamin; } \\
\text { Filosofia } \\
\text { contemporânea; } \\
\text { Estética; Filosofia } \\
\text { alemã. }\end{array}$ \\
\hline$\nabla$ & $\begin{array}{c}\text { 2012/ } \\
\text { Doutorado }\end{array}$ & $\mathrm{AV} / \mathrm{ME}$ & \begin{tabular}{|} 
Entre as artes \\
visuais e o \\
design: o \\
movimento \\
concreto e o \\
projeto na \\
atualidade \\
\end{tabular} & $\begin{array}{l}\text { Arlindo Antônio } \\
\text { Stephan }\end{array}$ & \begin{tabular}{|c|} 
Prof. $^{\text {a }}$ Dr. \\
Monica Baptista \\
Sampaio \\
Tavares
\end{tabular} & $\begin{array}{l}\text { USP/ } \\
\text { SP }\end{array}$ & $\begin{array}{l}\text { P.P.G em } \\
\text { Artes }\end{array}$ & $\begin{array}{l}\text { Artes visuais; } \\
\text { Design } \\
\text { Híbrido; } \\
\text { Meios digitais; } \\
\text { Movimento } \\
\text { Concreto; } \\
\text { Projeto. } \\
\end{array}$ \\
\hline in & 2011/ Mestrado & $\mathrm{AV} / \mathrm{ME}$ & \begin{tabular}{|c|} 
Pintura e \\
imagens \\
técnicas: um \\
olhar \\
contaminado e \\
convertido \\
\end{tabular} & Taigo Meireles & $\begin{array}{c}\text { Prof. Dr. Pedro } \\
\text { Alvim }\end{array}$ & $\begin{array}{l}\mathrm{UNB} / \\
\mathrm{DF}\end{array}$ & $\begin{array}{l}\text { P.P.G em } \\
\text { Artes Visuais }\end{array}$ & $\begin{array}{l}\text { Pintura; Imagens } \\
\text { técnicas; Percepção, } \\
\text { Pós-modernidade. }\end{array}$ \\
\hline
\end{tabular}




\begin{tabular}{|c|c|c|c|c|c|c|c|c|}
\hline b & 2011/ Mestrado & $\mathrm{AV} / \mathrm{ME}$ & $\begin{array}{c}\text { Limites da } \\
\text { imagem digital: } \\
\text { estudo de obras }\end{array}$ & Fernando Senra & $\begin{array}{c}\text { Prof. Dr. } \\
\text { Francisco Carlos } \\
\text { de Carvalho } \\
\text { Marinho }\end{array}$ & $\begin{array}{l}\text { UFMG/ } \\
\text { MG }\end{array}$ & $\begin{array}{l}\text { P.P.G em } \\
\text { Artes }\end{array}$ & $\begin{array}{l}\text { Digital; Real; } \\
\text { Virtual; Hipermídia; } \\
\text { Interatividade. }\end{array}$ \\
\hline$r$ & $\begin{array}{c}\text { 2008/ } \\
\text { Mestrado }\end{array}$ & $\mathrm{AV} / \mathrm{ME}$ & $\begin{array}{l}\text { O sincretismo } \\
\text { nas imagens } \\
\text { móveis: DVD } \\
\text { 'O universo da } \\
\text { arte - Fayga } \\
\text { Ostrower' }\end{array}$ & $\begin{array}{c}\text { Ana Laura } \\
\text { Rolim da Frota }\end{array}$ & $\begin{array}{c}\text { Prof. }^{\text {a }} \text { Dr. }{ }^{\mathrm{a}} \text { Ana } \\
\text { Alice Dutra } \\
\text { Pillar }\end{array}$ & $\begin{array}{l}\text { UFRGS/ } \\
\text { RS }\end{array}$ & $\begin{array}{l}\text { P.P.G em } \\
\text { Educação }\end{array}$ & $\begin{array}{c}\text { Arte-ensino; } \\
\text { Imagem-Leitura- } \\
\text { Representaçã; Mídia } \\
\text { digital-DVD; } \\
\text { Sincrestismo; } \\
\text { Semiótica } \\
\text { greimasiana } \\
\end{array}$ \\
\hline$\infty$ & 2006/ Mestrado & $\mathrm{AV} / \mathrm{ME}$ & $\begin{array}{c}\text { A obra artística } \\
\text { e as novas } \\
\text { mídias de } \\
\text { representação: } \\
\text { do papel ao } \\
\text { digital }\end{array}$ & $\begin{array}{c}\text { Débora Maria de } \\
\text { Paula Miller }\end{array}$ & $\begin{array}{l}\text { Prof. Dr. } \\
\text { Pelópidas } \\
\text { Cypriano de } \\
\text { Oliveira }\end{array}$ & UNESP/ SP & $\begin{array}{l}\text { P.P.G em } \\
\text { Artes }\end{array}$ & $\begin{array}{c}\text { Arte; Computação } \\
\text { gráfica; } \\
\text { Criatividade; Tablet; } \\
\text { Digital. }\end{array}$ \\
\hline a & 2006/ Mestrado & $\mathrm{AV} / \mathrm{ME}$ & $\begin{array}{l}\text { O ponto e o } \\
\text { pixel: novas } \\
\text { mídias, novas } \\
\text { linguagens }\end{array}$ & $\begin{array}{l}\text { Kleber Adriano } \\
\text { Silva e Oliveira }\end{array}$ & $\begin{array}{c}\text { Prof. Dr. Silvio } \\
\text { Melcer } \\
\text { Dworecki }\end{array}$ & $\begin{array}{l}\text { USP/ } \\
\text { SP }\end{array}$ & $\begin{array}{l}\text { P.P.G em } \\
\text { Design e } \\
\text { Arquitetura }\end{array}$ & $\begin{array}{l}\text { Comunicação visual; } \\
\text { Linguagem; Meios } \\
\text { de comunicação; } \\
\text { Imagem digital; } \\
\text { Multimídia } \\
\text { interativa; Tempo. }\end{array}$ \\
\hline
\end{tabular}

Fonte: Do autor, 2015

Para uma melhor compreensão de leitura da tabela 1, as siglas equivalem respectivamente à: no cabeçalho — Instituições (Inst.), Programa de Pós-graduação (P.P.G) —; em termos de busca - Crítica de arte/Mídia-educação (CA/ME), Artes visuais/Mídiaeducação (AV/ME) —; já em orientador — Professor Doutor (Prof. Dr.), Professora Doutora (Prof ${ }^{\mathrm{a}}$. Dr ${ }^{\mathrm{a}}$.) —; no que se refere às instituições — Universidade Federal de São Paulo, do estado de São Paulo (USP/SP), Universidade de Campinas, do estado de São Paulo (UNICAMP/SP), Pontifícia Universidade Católica, do estado de São Paulo (PUC/SP), Universidade Federal do Rio Grande do Sul, do estado do Rio Grande do Sul (UFRGS/RS), Universidade de Brasília, do estado do Distrito Federal (UNB/DF), Universidade Federal de Minas Gerais, do estado de Minas Gerais (UFMG/MG), e, Universidade Estadual Paulista "Júlio de Mesquita Filho", do estado de São Paulo (UNESP/SP).

A temática central das produções selecionadas contribui para a problematização do tema desta pesquisa. Problematização esta, que questiona se existe um vínculo entre os termos chave e de qual forma esse vínculo é discutido no meio acadêmico. Ao observar a tabela 2, é perceptível compreender sobre a localização geográfica na qual as produções acadêmicas foram publicadas. 
Tabela 2- Período de tempo e local das dissertações e teses

\begin{tabular}{c|c|c}
\hline \multirow{2}{*}{ ANOS } & DISSERTAÇÕES & TESES \\
\cline { 2 - 3 } & $2006 / 2008 / 2011 / 2012$ & $2008 / 2010 / 2012$ \\
\hline \multirow{2}{*}{ INSTITUIÇÕES } & $\begin{array}{c}\text { PUC/SP, UNB/DF, UFMG/MG, USP/SP, } \\
\text { UNESP/SP e UFRGS/RS }\end{array}$ & USP/SP e UNICAMP/SP \\
\hline \multirow{2}{*}{ P.P.G } & Comunicação e semiótica; Artes; Design e & Artes; Filosofia e Ciências; Cultura e \\
& arquitetura; Educação & Informação \\
\hline
\end{tabular}

Fonte: Do autor, 2015

$\mathrm{Na}$ tabela 2, as teses selecionadas foram defendidas por duas instituições do estado de São Paulo (USP e INICAMP), o que evidencia uma sistematização geográfica dos estudos que relacionam artes e crítica de arte com mídia-educação. Já, nas produções das dissertações é visto que, há uma concentração de pesquisa no estado de São Paulo (PUC, UNESP e USP), mas é evidente também registros de outros estados (UFMG, UFRGS e UNB) que discutem o assunto. As publicações estão associadas à diversos programas de pós-graduação, o que possibilita um discurso interdisciplinar e intercultural. Mas, também, evidencia a necessidade de um direcionamento direto das universidades em considerar a formação de um curso específico sobre o tema.

Em vista disso, é possível afirmar que a relação arte/educação e mídia-educação constitui um tema recente, de importante relevância para o estudo. Pois os mesmos, auxiliam no desenvolvimento pedagógico do ensino de Artes e na consciência crítica em relação à apreensão de conteúdo, tanto artísticos quanto midiáticos. Com um equilíbrio teórico e prático, o que propicia à produção, leitura, apreciação das imagens, e a criticidade dos elementos visuais decorrentes da arte contemporânea, formadores da cultura e dos discursos visuais da atualidade. E, isto pode ser visualizado nas análises e discussões das noves produções acadêmicas.

\section{ANÁLISES E DISCUSSÕES}

No que concerne à análise geral, entre dissertações e teses, mesmo que em menor quantidade, as teses contribuíram com mais rigor à teorização dos processos críticos das artes, que por meio da recepção de um público se aproxima dos conceitos que englobam a mídia- 
educação. Já as dissertações, apresentam processos teóricos e práticos, perpassando discussões sobre os meios de fazer tal relação.

Na tese 1, denominada de "O foco da crítica: arte e verdade na Correspondência entre Adorno e Benjamin”, do autor Lucianno Gatti, que está mapeada nos termos crítica de arte "and" mídia-educação (CA/ME), o autor desenvolve o conceito de crítica de arte, situando a década de 1930, e os pensadores, Adorno e Benjamin. Com uma visão interpretativa, o autor, elucida os pontos em comum na ideia da "crítica materialista" que os dois pensadores apresentam, quando confrontados com os elementos das artes na cultura de massa, interpostas pelo início do século XX. No qual o advento da pós-modernidade, a fotografia e o cinema, surgem como fenômenos de representações artísticas, "exigindo uma especial atenção ao rompimento da arte moderna com todo critério de avaliação transmitido pelo passado e externo à constituição das obras de arte.” (GATTI, 2008, p. 15)

Gatti, relaciona a arte com os critérios de apreciação, pontuando a expansão industrial e tecnológica, do tempo em discussão, ao contexto sociopolítico, econômico e cultural. E, discorre sobre a exigência da rearticulação constante da crítica em função da realidade transitória das interpretações dos objetos artísticos.

Em "Relato de outra modernidade: contribuições para uma reflexão crítica sobre a mediação da arte no contexto da globalização cultural”, de Vinícius Spricigo, que também foi mapeada nos termos de busca (CA/ME), objetiva como tema as transformações no modo de mediar a arte no contexto globalizado. Caracteriza uma sociedade de consumo, da cultura visual, que contribui para o paradigma da arte contemporânea e da "arte global". O autor evidencia o "efeito bienal", e utiliza como instrumento de análises o significado das bienais contemporâneas em centros não emergentes.

No atual contexto de 'crise de representação' e dúvidas acerca das mudanças que a globalização traz para a esfera da arte, esta Tese defende o emprego de um tipo de 'mediação cultural' baseado nas tecnologias da informação que possibilitam a ampliação do acesso ao conhecimento produzido nesse âmbito. Ou seja, além do componente comparativo entre a genealogia de duas das principais exposições internacionais de arte contemporânea do pós-guerra, a Bienal de São Paulo e a Documenta, e da análise da virada global da arte contemporânea, proposta por Hans Belting, esta pesquisa também incorpora os referencias teóricos da 'sociedade da informação' e da 'esfera pública conectada'. (SPRICIGO, 2010, p. 38) 
Ao concluir a tese, o autor deixa claro, que o potencial entre arte e mídias, ou tecnologias informacionais, demonstram um novo contexto formador e consolidador nas perspectivas críticas em uma escala global. Pontua que o público, está socialmente formado pela cultura conectada e a mediação da arte se faz necessária para o processo de apreensão, fruição e educação.

A tese 3, intitulada de "Entre as artes visuais e o design: o movimento concreto e o projeto na atualidade", do autor Arlindo Stephan, elaborada em 2012, está mapeada no termo de busca artes visuais "and” mídia-educação (AV/ME). E, aponta os aspectos da tecnologia e da imagem como tendências das artes visuais e a sua relação com as teorias estruturantes do design. Com uma abordagem que aproxima o potencial criativo artístico e visual proporcionado pelos avanços tecnológicos, a arte e o design se aproximam pelo processo de comunicação.

O autor, elabora a ideia de que a arte contemporânea entra em crise quando a sua produção se dá pela inadequação e a ineficácia dos meios de comunicação e informação, enquanto linguagens. Pontuando que, “ a cultura visual é mais disseminada pelos meios de comunicação, embora a imagem perca informação e seja alterada pelo processamento eletrônico." (STEPHAN, 2012, p. 84)

Por fim, conclui a pesquisa, percebendo que entre as décadas de 1950-1960, no Brasil, o movimento concretista das artes, estabeleceu uma relação entre arte e sociedade acelerada tecnologicamente. Discute o papel dos sujeitos no ambiente tecnológico e as suas identidades, percebendo que o público se encaminhado para uma percepção crítica, se beneficiaria na relação entre cultura das arte e culturas midiáticas.

A seguir, as produções analisadas correspondem à programas de pós-graduação de artes, educação, arquitetura e comunicação das dissertações mapeadas. Mantem uma linearidade no período de tempo de publicação, remonta à importância e à inovação do tema.

$\mathrm{Na}$ dissertação 1, intitulada “O ponto e o pixel: novas mídias, novas linguagens", está mapeada no termo de busca (AV/ME), do autor Kleber Oliveira em 2006, discute sobre as formas de expressão na comunicação e na arte, associando a linguagem visual ao campo da mídia como incentivador de novas expressões e potenciais criativos nas artes. Teoriza sobre o elemento, o ponto, como mínimo nas artes visuais sendo expressão de intenção e, configuração de movimentos ou equilíbrio estático, como observado em obras de arte concretas. Já o pixel, de acordo com o autor, é "uma tradução digital do ponto, está 
relacionada a um tipo de suporte que permite atualizações constantes e contínuas." (OLIVEIRA, 2006, p. 17)

O autor dialoga sobre o caminho cultural que se torna dependente da comunicação, das representações e da transitoriedade das linguagens. Problematiza a construção poética das artes quando o uso de novas mídias ou a mestiçagem delas ocorrem no processo de criação. Esta adquire caráter híbrido, pela fusão das linguagens, uma interpretação que propicia uma interpretação, uma leitura das obras de arte. Conclui a dissertação analisando os signos como símbolos que são utilizados nas artes como elementos, que se repetidos convergem à uma expressividade inerente à arte digital.

Já em “A obra artística e as novas mídias de representação: do papel ao digital, também mapeada no termo de busca (AV/ME), a autora Débora Miller, busca refletir sobre o modo de fazer obras de arte através dos meios digitais. Propulsionando e percebendo as mudanças nas possibilidades técnicas. Utilizou de sua experiência poética nas artes e propôs uma experimentação ao usar novos meios tecnológicos para criar. Miller (2006, p. 52), afirma que "a integração deste conjunto de realizações, aliado às bases técnico/teóricas utilizadas no desenho artístico tradicional, propiciou a elaboração e obtenção dos mais variados resultados em imagens digitais [...]."

Em sua conclusão, sobre a relação entre arte e mídias, a autora percebeu que os aspectos plásticos das obras de arte digital ainda apresentam fundamentos da arte clássica, na qual, “ a arte digital é uma forma de manifestação artística bastante recente e ainda muito pouco explorada, mas que já apresenta algumas particularidades específicas que a transformam, bem como a seus processos de criação, estabelecendo assim um expressivo diferencial entre a arte produzida com meios tradicionais e com mídias digitais." (MILLER, 2006, p. 134-135)

A dissertação 3, denominada de "O sincretismo nas imagens móveis: DVD “ $\mathrm{O}$ universo da arte - Fayga Ostrower"”, a autora Ana Laura Frota, está mapeada no termo de busca (AV/ME) e, discute sobre a percepção das ações pedagógicas através do uso das imagens. Percebendo que a tecnologia, e a visualidade fornecem atratividade aos jovens, a autora demonstra a importância da influência e da utilidade de vídeos para se propiciar a educação. Por meio de um estudo de campo, Frota, tentou compreender como as imagens móveis influenciam as pessoas.

Ao discorrer sobre as influências midiáticas, Frota (2008, p. 57), também analisa as questões relacionadas ao ensino de arte. Relacionando o uso da mídia na educação, 
evidenciando que “o uso das mídias, nas práticas escolares, assume o caráter de um aprendizado poderoso, evidenciado nos discursos orais e escritos, assim como nas visualidades e sons - ruídos e melodias - que contêm."

Conclui observando a necessidade do desenvolvimento pedagógico que une arte e mídia, promovendo construções de significados, leituras críticas, e apreensões de sentidos, onde os sujeitos do processo, artistas, professores, público emergem e se conectam visualmente através de suas experiências transitórias.

Em "Limites da imagem digital: estudo de obras", que está mapeada no termo de busca (AV/ME), o autor Fernando Senra aborda, que os processos da imagem digital, possibilitadas pela tecnologia, permitiu flexibilidade e dinamismo na produção e percepção das mesmas. A manipulação proporcionada por programas específicos, auxiliariam no processo interativo de criação.

$\mathrm{O}$ autor analisa a modalidade artística cinematográfica e a define como produtora de possibilidades cognitivas, na qual a imagem adquire a capacidade de modificar estruturalmente, permitindo também a produção da realidade expandida. Aproxima a ideia de que as imagens digitais estão mais próximas dos indivíduos quando, "são incorporadas aos aplicativos e dispositivos utilizados no dia a dia, em mídias móveis, como telefones celulares, pads, etc." (SENRA, 2011, p. 23)

Conclui, abordando que a relação arte e mídia, se dinamizam. A imagem adquire processo interativo e tornam-se ferramentas para o processo criativo da arte. O limite entre a relação é fluídico e dinâmico, está atuante e integra a realidade atual. Sendo complexa e diversa, o mundo digital e a leitura das imagens nesse meio proporcionam uma ampliação nas experimentações reais e imagéticas dos indivíduos.

Também mapeada pela pesquisa, pelo termo de busca (AV/ME), a produção acadêmica, "Pinturas e imagens técnicas: um olhar contaminado e convertido", é o título da dissertação de Taigo Meireles que, averigua sobre a relação entre pinturas e fotografias com o uso de outras mídias contemporâneas formadoras de discursos poéticos das artes. Pontua a amplitude de informação visual, que na atualidade percorre os olhares dos sujeitos, e questiona a dinâmica dessas imagens e qual os seus valores.

Apoiado por referencial teórico e por meio de análise das imagens, o autor comenta sobre as técnicas de pintura e fotografia, modernas e contemporâneas. Salienta que cada mídia apresenta sua forma de expressão, e que a rapidez tecnológica ampliou o número de informações. Taigo (2011, p.104), afirma que: 
[...] Comunicar é impossível, resta apenas a possibilidade de gerar sensações e, ainda assim, corre-se o risco de estimular sensações prontas, pré-fabricadas, preparadas e condicionadas por programas culturais fundados na publicidade de massa, como novelas, filmes românticos, propagandas de cigarro, enfim, por toda sorte de produções que possuem efeitos preestabelecidos por uma linguagem que se torna, a cada dia, mais programática e desumanizada.

Conclui, revelando que a sociedade está condicionada a exposição constante de informação, mas que os profissionais de arte, com essa revolução midiática recebeu acesso às dimensões de realidade diferentes e mais amplas. Isto gerou resultados estéticos transitórios e autênticos na cultura visual e imagética.

Por último e mais atual, a dissertação 6, está mapeada no termo de busca (CA/ME) é intitulada de "AaaS: uma nova condição para criar, conhecer, comunicar, da autora Vanessa Lopes, que discute como a arte contemporânea transita para uma desestabilização quanto as classificações de gêneros das artes. Não há limites para utilização de suportes, e compartilhamentos e comunicabilidade para com o público. A autora afirma que, "inserida numa cultura tecnocrática e midiática, a arte reinventou seus modos de ser e estar no mundo, principalmente a partir do surgimento da cultura digital e da comunicação em rede [...].” (LOPES, 2012, p. 9)

A sua pesquisa foi elaborada por experiências próprias de artista e produtora de cultura, no qual a transitoriedade de linguagens e a hibridização foram apreendidas para construir o caminho artístico. Evidencia a dificuldade de relacionar os estudos de arte e crítica com o estudo das mídias, e comunicação. Fato que comprova a incipiência no assunto arte relacionada com mídia-educação. Devido, sobretudo, à amplitude de definições terminológicas sobre mídia.

Em sua conclusão, a autora, esclarece que o termo "AaaS" (Art as a Service), utilizado no título do trabalho, surgiu a partir da necessidade de colocar a arte a serviço das mídias e seus colaboradores. Percebendo que o consumo na contemporaneidade pode ser aproximado das questões artísticas.

Com isso, é possível observar que, existe uma relação entre os termos arte e mídiaeducação, mesmo que de forma indireta. Algumas apropriam os termos e os associam com as questões do ensino, outras discutem sobre experiências estéticas que culminam na aproximação entre as culturas artísticas e midiáticas. 


\section{CONCLUSÃO}

As análises das produções acadêmicas, teses e dissertações, mapeadas e selecionadas através do Portal CAPES/MEC, que apresentam conjunção com os termos de busca e com o objetivo desta pesquisa, apontou a dificuldade e a exiguidade de uma relação direta entre os conceitos de arte/educação com mídia-educação. Foram diagnosticas 35 pesquisas inicialmente, sendo apenas selecionadas 09 para análises, cujos temas desenvolviam a aproximação, ou apontavam uma perspectiva, para a integração da arte e da crítica de arte com a mídia-educação.

Dessa maneira, é possível concluir que as produções apresentam uma vivência e uma apropriação do tema, ora utilizando os elementos da arte visuais com os conceitos tecnológicos, ora discutindo sobre crítica de arte para elaborar preceitos sobre a globalização e as influências midiáticas. A educação nesse sentindo é envolvida de forma insuficiente, promovendo a necessidade de pesquisas que atuem, praticamente, na formação de docentes e discentes, abordando uma visão crítica para a apreensão e fruição da linguagem visual.

Arte/educação e mídia-educação são saberes que evidenciam demandas direcionadas para o estudo das manifestações contemporâneas no ensino de artes. Estas demandas se constituem a partir das novas vertentes metodológicas no ensino da arte. Ressaltando as influências das mídias na socialização dos sujeitos, destacando um movimento contemporâneo identificado como cultura visual.

Na resolução $n^{\circ}$ 2/2012, do MEC/CNE/CEB que define as Diretrizes Curriculares Nacionais para o Ensino Médio, é perceptível a possibilidade de articulação entre arte e mídia, no qual o projeto político-pedagógico das escolas deve considerar, segundo o artigo 16 e seus itens I, VIII e XX respectivamente como:

[...] as atividades integradoras artístico-culturais, tecnológicas e de iniciação científica, vinculadas ao trabalho, ao meio ambiente e à prática social; a utilização de diferentes mídias como processo de dinamização dos ambientes de aprendizagem e construção de novos saberes; e, a produção de mídias nas escolas a partir da promoção de atividades que favoreçam as habilidades de leitura e análise do papel cultural, político e econômico dos meios de comunicação na sociedade. (MEC/CNE/CEB, 2012, p. 6-7)

Pensando na articulação do ensino de artes com os métodos da mídia-educação, esta pesquisa evidencia a potencial discussão para nortear de forma intercultural e transitória o 
ensino de arte, da crítica de arte associadas com as metodologias da mídia-educação. Esta relação é atual e constitui como tema recente.

Os mesmos, auxiliam no desenvolvimento pedagógico e cognitivo do ensino de artes e na consciência crítica e alfabetizada dos conteúdos artísticos e midiáticos. A arte e a mídia têm importância na criação e difusão do ensino e na construção do caráter indenitário da cultura, possuem papéis para formadores que provocam o conhecimento unindo teoria e prática, o que propicia à produção, leitura e apreciação se possibilitadas pelos valores críticos dos sujeitos.

\section{REFERÊNCIAS}

BARBOSA, A. M. A cultura visual antes da cultura visual. Educação, Porto Alegre, v. 34, n. 3, p. 293-301, set./dez. 2011.

BARBOSA. A. M.; COUTINHO, R.G. Arteleducação como mediação cultural e social. São Paulo: Ed. UNESP, 2009.

BÉRVOT, E; BELLONI, M. A. Mídia-educação: conceitos, história e perspectivas. Ed. Soc., Campinas, vol. 30, n. 109, p. 1081-1102, set./dez. 2009.

BUCKINGHAM, D. Cultura digital, Educação Midiática e Lugar da escolarização. Educ. Real., Porto Alegre, v. 35, n. 3, p. 37-58, set./dez. 2010.

CAUQUELIN, A. Teorias da arte. São Paulo: Ed. Martins, 2005.

COLI, J. O que é arte. São Paulo: Ed. Brasiliense, 1995.

DESSAUCY, J. Mass media education or education for communication. International Commission for the Study of Communication Problems - paper number 72. Paris: UNESCO, 1978. Disponível em <http://www.unesco.org/ulis/cgibin/ulis.pl?catno=49243\&set=4EC12471_3_447\&gp=1\&lin=1\&1l=1>. Acesso em: $07 \mathrm{Fev}$. 2016.

DOMINGUES, J. L. P.; SOUZA, V. N. de. Programa Cultura Viva: A política cultural como politica social? Elementos de análise dos fundos públicos e do direito à produção da cultura. In: Anais do V Encontro de Estudos Multidisciplinares em Cultura. Salvador, 2009.

Entrevista com Ana Mae Barbosa. Memória Roda Viva, São Paulo: TV Cultura, 12 de outubro de 1998. Programa de TV. Disponível em: 
$<$ http://www.rodaviva.fapesp.br/materia/370/entrevistados/ana_mae_barbosa_1998.htm> Acesso em: 28 de maio de 2015.

FERREIRA, Norma Sandra de Almeida. As pesquisas denominadas "estado da arte". Revista Educação \& Sociedade, Campinas, n. 79, p. 257-272, Ago, 2002.

FROTA, A. R. L. da. O sincretismo nas imagens móveis: DVD “O universo da arte - Fayga Ostrower. 2008. Dissertação (Mestrado em Educação) - Universidade Federal do Rio Grande do Sul, Porto Alegre, 2008.

GATTI, L. F. O foco da crítica: arte e verdade na Correspondência entre Adorno e Benjamin. 2008. Tese (Doutorado em Filosofia e Ciências) - Universidade de Campinas, Campinas, 2008.

HALLORAN, J.D.; JONES, M. Learning about media: communications and society. Paris: UNESCO, 1986. Disponível em: < http://unesdoc.unesco.org/images/0007/000712/071267EB.pdf>. Acesso em: 19 out. 2015.

JENKINS, H. Cultura da Convergência. São Paulo: Aleph, 2008.

KELLNER, D.; SHARE, J. Educação para leitura crítica da mídia, democracia radical e a reconstrução da educação. Educ. Soc., Campinas, v. 29, n. 104 - Especial, p. 687-715, ou. 2008.

LOPES, V. AaaS: uma nova condição para criar, conhecer, comunicar. 2012. Dissertação (Mestrado em Comunicação e Semiótica) - Pontifícia Universidade Católica, São Paulo, 2012.

MILLER, D. M de P. A obra artística e as novas mídias de representação: do papel ao digital. 2006. Dissertação (Mestrado em Artes) - Universidade Estadual Paulista, São Paulo, 2006.

OLIVEIRA, K. A. S. O ponto e o pixel: novas mídias, novas linguagens. 2006. Dissertação (Mestrado em Design e arquitetura) -Universidade de São Paulo, São Paulo, 2006..

SENRA, F. Limites da imagem digital: estudo de obras. 2011. Dissertação (Mestrado em Artes) - Universidade Federal de Minas Gerais, Belo Horizonte, 2011.

SPRICIGO, V. P. Relato de outra modernidade: contribuições para uma reflexão crítica sobre a mediação da arte no contexto da globalização cultural. 2010. Tese (Doutorado em Cultura e Informação) - Escola de Comunicações e Artes, Universidade de São Paulo, São Paulo, 2010. 
STEPHAN, A. A. Entre as artes visuais e o design: o movimento concreto e o projeto na atualidade. 2012. Tese (Doutorado em Artes) - Escola de Comunicações e Artes, Universidade de São Paulo, São Paulo, 2012.

TAIGO, M. Pintura e imagens técnicas: um olhar contaminado e convertido. 2011. Dissertação (Mestrado em Artes) - Universidade de Brasília, Brasília, 2011.

UNESCO. Um mundo. Muitas vozes - Comunicação e informação na nossa época. Rio de Janeiro: Editora da Fundação Getúlio Vargas, 1983.

WILSOM, C. Alfabetização midiática e informacional: currículo para formação de professores. Brasília: UNESCO, UFTM, 2013.

RECEBIDO EM: 03/03/2016

APROVADO PARA PUBLICAÇÃO EM: 29/06/2016 